\title{
A review of the potential of renewable energy sources for the State of Jammu and Kashmir (India)
}

\author{
Arsalan Nisar Carlos Rodríguez Monroy
}

\begin{abstract}
A B S T R A C T
The future economic development trajectory for India is likely to result in rapid and accelerated growth in energy demand, with expected shortages. Many of its current policies and strategies are aimed at the improvement and possible maximization of energy production from the renewable sector. It is also clear that while energy-conservation and energy-efficiency can make an important contribution in the national energy strategy, renewable energies will be essential to the solution and are likely to play an increasingly important role for the growth of grid power, providing energy access, reducing consumption of fossil fuels, and helping India pursue its low carbon progressive pathway. However, most of the states in India, like the northernmost State of Jammu and Kashmir (J\&K), have experienced an energy crisis over a sustained period of time. As India intends to be one of the emerging powers of the $21 \mathrm{st}$ century, it has to embark upon with these pressing issues in a more sustainable manner and accordingly initiate various renewable energy projects within these states. This paper will provide a broad-spectrum view about the energy situation within J\&K and will highlight the current policies along with future strategies for the optimal utilization of renewable energy resources.
\end{abstract}

\section{Introduction}

India has recorded impressive rates of economic growth in recent years, which provide the basis for more ambitious achievements in the future. However, a healthy rate of economic growth equaling or exceeding the current rate of $8 \%$ per annum would require major provision of infrastructure and enhanced supply of inputs such as energy. High economic growth would create much larger demand for energy and this would present the country with a variety of choices in terms of supply possibilities (TERI, 2006).

The inadequate availability of energy continues to confine India's sustained growth and economic competitiveness. While India's GDP has grown at an average of about $8 \%$ per annum over the last six years, electricity generation/supply has grown at only an average of $5.3 \%$ per year. Electricity shortages are estimated to cost the country around 7\% of GDP (World Bank, 2010).

Apart from certain central institutions such as the National Thermal Power Corporation (NTPC) ${ }^{1}$ and Powergrid, ${ }^{2}$ most State power utilities operate without autonomy and under diffuse accountability systems. They suffer from limited implementation capacities, a shortage of skilled manpower, and poor financial standing due to inadequate tariffs that do not recover the production costs.

While the Government of India is working to strengthen the public sector's capacity, it is also encouraging a paradigm shift to scale-up public-private partnerships (PPP) in the electricity sector. So far, only $15.5 \%$ of grid-based generation and $12 \%$ of distribution is currently handled by the private sector (World Bank, 2010).

In order to tackle these problems a large number of programmes and initiatives have been started and the government at all different levels (local, state and national) needs to achieve these targets through sustainable means by encouraging renewable technologies (Bhide and Rodríguez-Monroy, 2010).

\subsection{Structure and contents}

The paper provides a brief overview of Jammu and Kashmir and presents the current energy situation in the region. It highlights the 
present problem regarding the energy supply-demand situation by endorsing the need for renewable sources. Accordingly, the current status and potential of different renewable energy sources such as solar-, hydro-, geothermal- and wind-power are presented. To conclude, the barriers to renewable energy policy development and diffusion are highlighted along with some helpful conclusions and recommendations.

\section{The State of Jammu and Kashmir and the current energy situation}

Jammu and Kashmir is the northernmost State of the Union of India, lying between six mountain ranges and covering an area of 222,236 square kilometers.

Jammu and Kashmir commonly known as Kashmir shares a border with the states of Himachal Pradesh and Punjab to the south and internationally with the People's Republic of China to the north and east and the Pakistan-administered territories of Azad Kashmir and Gilgit-Baltistan, to the west and northwest, respectively. The state accounts for $3.2 \%$ of the total geographic area of India and $1 \%$ of the total population of India. J\&K consists of three territorial divisions: Jammu, Kashmir valley and Ladakh, and is further divided into 22 districts (Fig. 1).

$\mathrm{J} \& \mathrm{~K}$ is one of the energy-starved states within India and the inadequacy of power has been affecting the pace of development in all sectors of the economy. The state has a unique position in the power generation and power market within northern India. Its rivers, which are the main source of power generation, have the maximum flow during the summer season (April-October) and thus have a potential to meet the pressing energy demands. However, during the rest of the year, i.e. in the winter season, the water level drops to one third of the annual average and the demand increases due to the extra usage of electricity for heating and lighting purpose and thus resulting in purchase of large quantities of power from adjacent states. This has placed the State finances in a deficit situation. During the fiscal year 2008-2009 alone, only $29 \%$ of the power was produced within the State, while the rest was purchased, thus creating large differences in revenue and income.

The figures for the last ten years indicate that energy poverty has created a lot of pressure on the limited forest reserves and the State government has been forced to buy energy resources to meet the demand during the winter season, when the gap between demand and supply is highest.

From the year 1990 to 2005 , the energy demand in J\&K grew by $3.5 \%$ per year, but the State recorded a deficit of more than $20 \%$

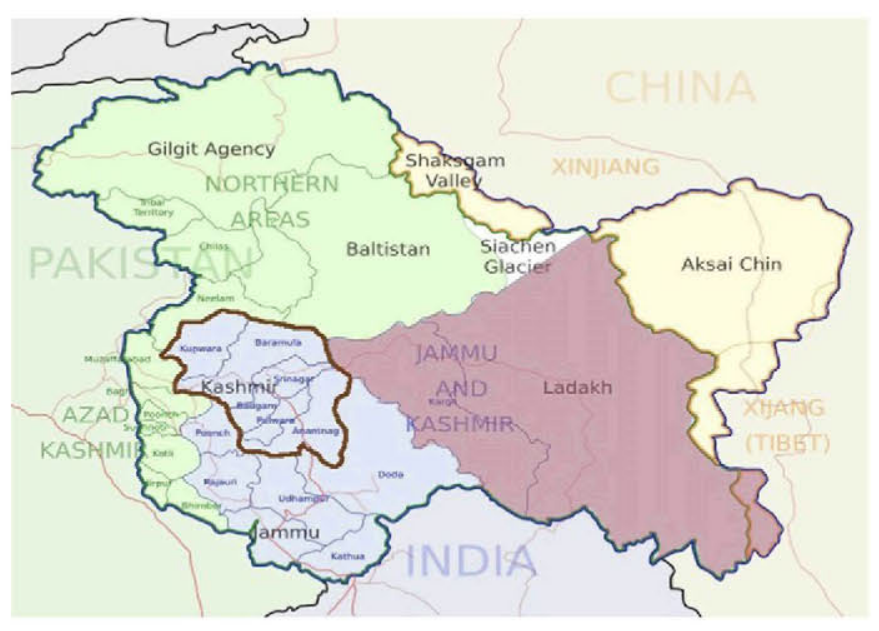

Fig. 1. Map of Jammu and Kashmir. in the availability of power during peak hours a deficit is expected to increase in the future if major steps towards the development and exploitation of renewable resources are not taken. Hence, there is strong need to design various renewable energy policies that can contribute to solve the persistent energy problems of Jammu and Kashmir (Fig. 2).

\section{The energy problem}

The State of Jammu and Kashmir has the legacy of State-owned vertically integrated electricity supply industries, often with lobbying of tariff setting that leads to excessively cheap electricity for domestic consumers, high levels of non-technical losses (i.e. theft or failure to collect bills), high levels of debt or arrears, and poor commercial performance as a measure of ability to collect revenues to cover costs. As a result, it is difficult for the sector to finance its investment needs on commercial terms, and often suffers from poor maintenance with frequent equipment failures (e.g. as measured by transformer failures and low generation availability), with power shortages and frequent load shedding (Newbery, 2006).

\section{The need for renewable energy sources}

As the State is primarily dependent on fossil fuels for its energy requirements, the exhaustible nature along with the volatile market prices further contribute towards its energy insecurity of supply. The State government needs to recognize the central role of energy and the need to have a set of policies that promote efficient use of conventional energies coupled with proactive realization of non-conventional energy resources and thus reduce greenhouse gas (GHG) emissions to achieve sustainable growth. As shown in Fig. 3, there is considerable potential for renewable energy resources in north India.

\begin{tabular}{ll}
\hline Power Demand and Availability & \\
\hline & \\
\hline Unrestricted Peak Power Demand MW & 2120 \\
\hline Peak Demand met MW & 1458 \\
\hline Peak Deficit MW & 662 \\
\hline Peak Deficit \% & $31.23 \%$
\end{tabular}

\section{Source: JKSPDC 2009 -}

Fig. 2. Power Scenario in Jammu and Kashmir by the end of 2009.

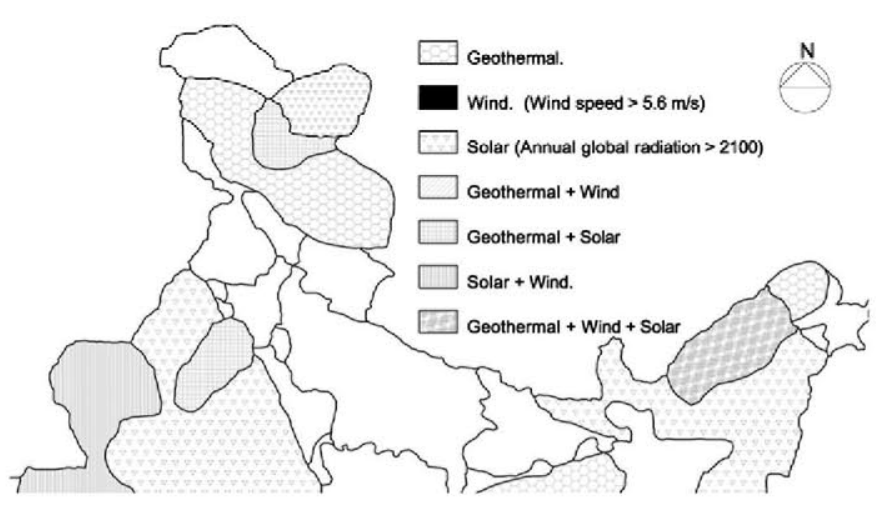

Fig. 3. Renewable resource map of north India, indicating the potential of solar and geothermal sources. 


\section{The status of solar power and wind energy}

In 2009, India launched a plan to become a global leader in solar energy by unveiling the Jawaharlal Nehru National Solar Mission. India has an ambitious plan to massively increase its installed, grid-connected solar capacity by the end of 2022 .

As a result, the State government of Jammu and Kashmir introduced the "Solar Power Policy-2010" with the following main objectives:

- To promote generation of green and clean power in J\&K using solar energy.

- To put in place an appropriate investment procedure that could leverage the Clean Development Mechanisms (CDM).

- To promote R\&D in order to facilitate technology transfer.

In addition, REEEP (Renewable Energy and Energy Efficiency Partnership) in association with the IFE (Institute of Energy Technology) of Norway is working closely with MNRE (Ministry of Renewable Energy, India) to promote renewable energy in the form of solar energy, particularly addressing rural energy deployment in India. Many villages within the State of Jammu and Kashmir are on the agenda along with other States of Madhya Pradesh, Jharkhand, etc. (TERI, 1999; JAKEDA, 2009). The New and Renewable Energy Ministry on India (MNRE, 2011) has estimated the solar energy potential at $20,000 \mathrm{MW}$ by the year 2020. Most of the solar potential lies in the north-eastern area of Ladakh.

In addition to solar power as a potential source of renewable energy, wind energy is practically untapped as a major renewable energy resource and thus venturing into this would be beneficial for the existing and consequently for future energy demand. Recently, the Ministry of New and Renewable Energy (MNRE, 2011) has devised plans for bringing renewable energy projects to the State with a strong focus on wind energy.

The Central Electricity Regulatory Commission (CERC) lately passed new regulations, encouraging stronger participation from the private sector and inviting greater Foreign Direct Investment (FDI) by providing higher return on investments and other relevant incentives. These new initiatives will strongly benefit the State of J\&K, as it presents itself with considerable potential for wind energy.

\section{Geothermal potential}

The geothermal resources in India have not been exploited commercially for heat or power generation. They have been mapped and the Geological Survey of India estimates the potential to be of the order of $10,000 \mathrm{MW}$. Most of the current usage of geothermal energy is for bathing and swimming. Chandrasekhar and Chandrasekharam (2010) estimates an installed capacity of $200 \mathrm{MW}$ (thermal) with an annual energy use of $1600 \mathrm{TJ} / \mathrm{year}$ and

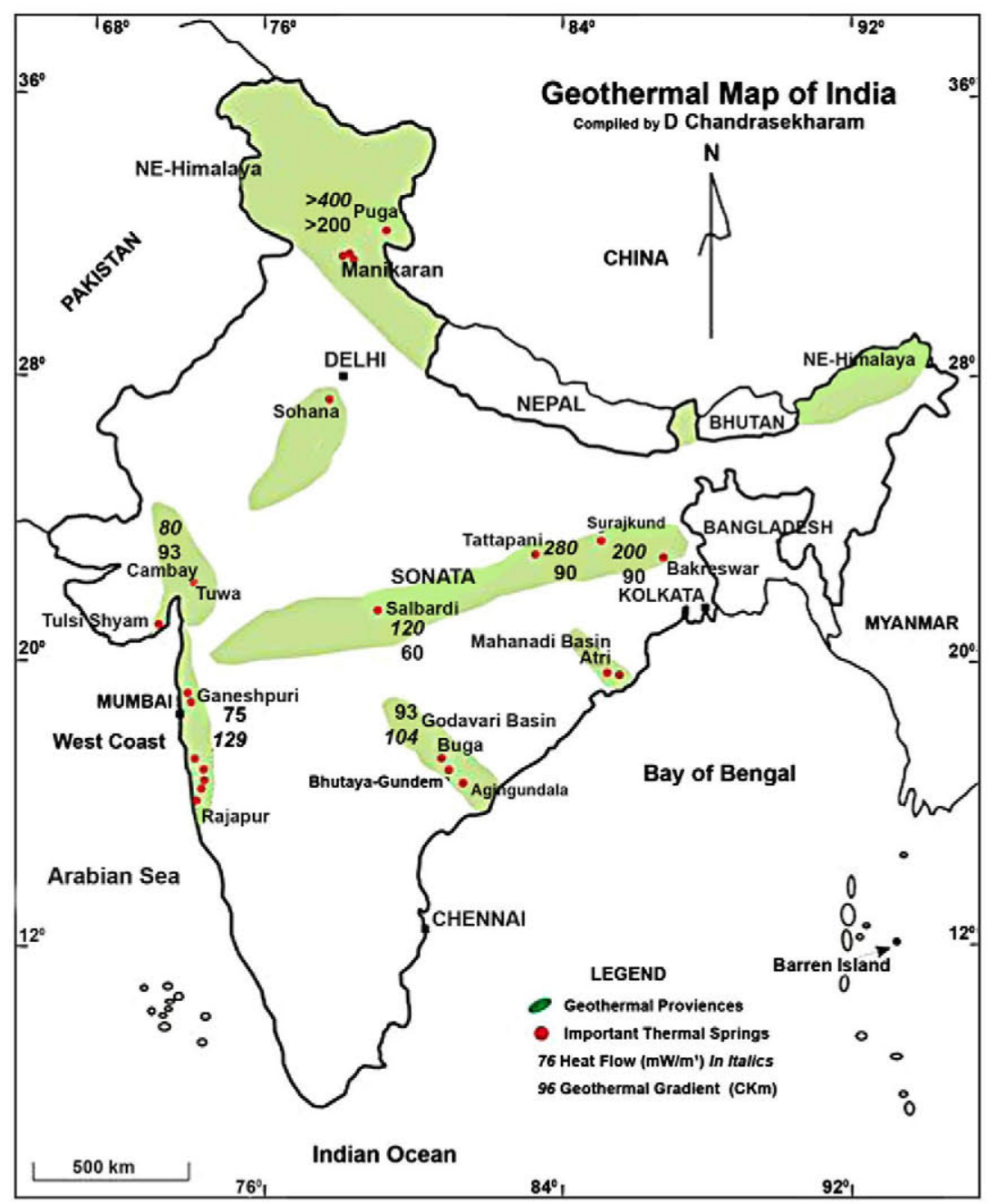

Fig. 4. Geothermal map of India by Chandrasekhar and Chandrasekharam (2010). 
a capacity factor of $25 \%$. It is expected that the geothermal sources can be used for lowgrade heating and direct utilization in various commercial industries.

In Ladakh, the northeastern part of Kashmir, demonstrations of heat pumps are planned and a $50 \mathrm{MW}$ power plant is planned in the Puga valley. Fig. 4 shows the potential for geothermal energy in India.

\subsection{Case study: hybrid power system in Ladakh region}

Ladakh is a remote region located in the Himalayas with very low population density. It is the northeastern part of Jammu and Kashmir. Small scattered loads and good availability of renewable energy resources like hydro, solar, wind and geothermal makes the region ideal for renewable energy based decentralized power generation. At present hydro and solar energy play an important role in power generation and rural electrification in Ladakh. Hydroelectricity from small hydroelectric plants (installed capacity $8.5 \mathrm{MW}$ ) accounts for about $60 \%$ of the total electricity generation. Currently, approximately 7000 solar photovoltaic (PV) domestic lighting systems provide electricity for lighting to about $25 \%$ of the households in Ladakh (Hiremath et al., 2009).

\section{The hydro potential}

J\&K has a hydropower potential of the order of $20,000 \mathrm{MW}$ of which about $16,000 \mathrm{MW}$ have been identified, and a mere $12 \%$ i.e. about $2336 \mathrm{MW}$ has been harnessed so far. The following chart depicts the basin-wise identified and harnessed potential (Fig. 5).

Ironically, this huge hydropower potential has not been fully exploited due to the shortage of financial resources and also as a consequence of the provisions in accordance to the Indus Water Treaty ${ }^{1}$ signed between India and Pakistan. The Indus runs through both India and Pakistan and comprises three western rivers the Indus, the Jhelum and Chenab and three eastern Rivers, the Sutlej, the Beas and the Ravi. The treaty restrains the right of J\&K on the upper Chenab, Jhelum, and Indus for purposes of consumptive hydroelectric storage and diversions within these basins.

However, the Government of Jammu and Kashmir (GOJK) has decided to encourage generation of power through small hydropower sources of energy and has framed a policy so that the development of this sector serves as a driving factor to achieve the objective of promoting the all-round development of the region (JKSPDC, 2010).

The Government of J\&K established the Jammu and Kashmir State Power Development Corporation Limited (JKSPDCL) in the year 1995 and has the responsibility to take over, execute, complete, operate, and maintain all power stations and power projects of the State. All power projects assets in the State, both existing and under implementation, were transferred to the corporation. The corporation presently has 18 hydroelectric projects with installed capacity of $305 \mathrm{MW}$ located in the various districts (JKSPDC, 2010).

\section{Future plans regarding hydropower}

The State of J\&K is planning to develop some 310 hydropower projects in order to meet the region's growing power requirements over the next two decades.

The above-mentioned hydro potential is estimated at about 20,000 MW. 64 of the 310 projects will be developed in the first phase of the initiative. Power projects with capacity above $200 \mathrm{MW}$ are being assigned to the state-run National Hydroelectric Power Corp (NHPC), while mini-hydropower projects are going to be developed through institutional power promoters and local companies. Another part of the initiative to increase hydropower capacity is to turn towards more energy-efficient processes, which will also help the State to conserve electricity (Planning Commission of India, 2010).

\section{Barriers in renewable energy development and penetration}

J\&K is one of the states that have the furthest to go in improving its energy efficiency. The loss in electricity distribution is important and needs to be addressed at substantial investment (IFRI, 2009).

The key factors affecting the success of the discussed renewable energy policies and programmes are the limited scope that they have and the poor performance they display. Very often the slow dissemination of technologies and the high subsidies on commercial fuels make the economics of renewable energy appear more unfavorable than what they are in reality. Also, inadequate budgetary allocations for the renewable sector make it hard for these policies to thrive.

On the positive side, a recent study by a team of scientists at Kashmir University has estimated J\&K's Clean Development

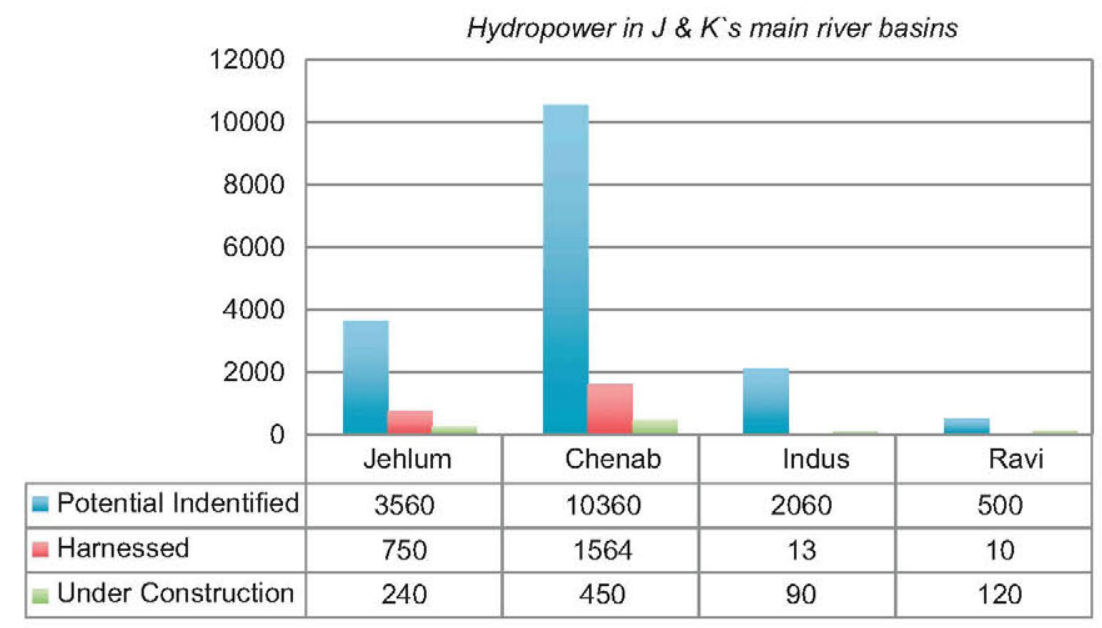

Fig. 5. Hydropower in J\&K's main river basins.

Source: JKSPDC, 2010. 
Mechanisms (CDM) potential at 75 million Certified Emission Reduction (CER) credits per annum. CDMs, which have been defined in Article 12 of the Kyoto Protocol, ${ }^{3}$ allow a country with an emission-reduction commitment under the Kyoto Protocol to implement an emission-reduction project in developing countries. Such projects can earn saleable (CER) credits, which can be counted towards meeting Kyoto targets (UNFCC, 2010a, 2010b).

According to experts, the only requirement for the State to sell its carbon credits would be to attain CDM certification for its projects in different energy sectors from the United Nations. On approval, these credits can be sold to developed nations, which under the Kyoto Protocol ${ }^{3}$ will have an obligation to invest in green technologies in developing countries. In addition, the research study suggests that if immediate efforts are made to exploit the CDM potential of the State, it could harness significant amount of hydropower in the next decade and partially solve the current energy scarcity.

\section{Conclusions and recommendations}

This study attempts to review and discuss the status, potential and opportunities of Kashmir in harnessing renewable energies. The State is facing acute scarcity of power, which can be gauged from the fact that against a total peak requirement of about $2000 \mathrm{MW}$, the state has been able to produce only $789 \mathrm{MW}$ by 2008. In addition, according to the available data there are about 2000 un-electrified villages within the State.

The wide gap between demand and supply of energy can be reduced through private sector participation and FDI. Considering the region's vast potential to harness renewable resources and the Central Government's efforts to promote clean energy, investment in this sector promises high returns.

In the short term, the renewable energy potential in the form of hydro should be exploited through environmentally clean micro- $(100 \mathrm{~kW})$, mini- $(100 \mathrm{~kW}-5 \mathrm{MW})$ power plants and subsequently develop larger (5-25 MW) plants. This policy of developing micro- and mini-plants has witnessed some success in other parts of India, like Uttarakhand, that have considerable potential but lack the necessary investment and development.

Small hydropower development should be taken as a part of rural electrification and poverty alleviation programs. Measures such as speeding up clearance of private power projects, de-licensing power generation from small hydro and providing investment support will encourage private participation. A bottom-up approach needs to be implemented for demonstration, awareness and training programs. In addition micro-credit lending and funding access can be extremely positive (Ghosh et al., 2001).

One of the main problems is the absence of private investment as it lacks positive investing opportunities. Power generation, transmission, and distribution companies and investment companies can play a major role in reducing the environmental degradation in J\&K by bringing sustainable energy facilities to

${ }^{3}$ The Kyoto Protocol is an international agreement linked to the United Nations Framework Convention on Climate Change. The major feature of the Kyoto Protocol is that it sets binding targets for 37 industrialized countries and the European community for reducing greenhouse gas (GHG) emissions. This amount to an average of five percent against 1990 levels over the five-year period 2008-2012.

Under the Treaty, countries must meet their targets primarily through national measures. However, the Kyoto Protocol offers them an additional means of meeting their targets by way of three market-based mechanisms.

The Kyoto mechanisms are: Emissions trading - known as "the carbon market", Clean development mechanism (CDM), Joint implementation (JI). The mechanisms help stimulate green investment and help Parties meet their emission targets in a cost-effective way (UNFCC, 2010). the region. The objective of the State government in the long run should be to make the conditions attractive for private investment/community participation in power projects based on renewable energy sources. Hence there is an urgent need for sustainable and active energy policies, which must be constituted by long- and short-term financial instruments (Rodríguez Monroy and San Segundo Hernández, 2008).

In addition, the Central and State Government have demonstrated its serious concern for the growing energy needs and the importance of renewable energy policies and programmes. These initiatives represent an important, but nonetheless fractional approach to addressing the problem. In order to tackle these pressing energy issues, a comprehensive, overarching vision must be articulated. Energy policy makers and planners need to shift from their traditional centralized, target-based, technologydriven and top-down approach towards a more decentralized and participatory approach (Neudoerfer et al., 2000).

\section{References}

Bhide, A., Rodríguez-Monroy, C., 2010. Energy poverty: a special focus on energy poverty in India and renewable energy technologies. Renewable and Sustainable Energy Review. doi:10.1016/j.rser.2010.11.044.

Chandrasekhar, V., Chandrasekharam, D., 2010. Energy independence through CDM using geothermal resources: Indian scenario. In: Proceedings World Geothermal Congress 2010 Bali, Indonesia, 25-29 April 2010.

Ghosh, D., Shukla, P.R., Garg, A., Ramana, P.V., 2001. Renewable energy strategies for Indian power sector. Centre de Sciences Humaines (CSH) Occasional Paper no. 3/2001, A publication of the French Research Institutes in India, New Delhi, India.

Hiremath, R.B., Bimlesh Kumar, P., Balachandra, Ravindranath, N.H., Raghunandan, B.N., 2009. Decentralised renewable energy: scope, relevance and applications in the Indian context. Journal of Energy for Sustainable Development 13, 4-10.

IFRI, 2009. Energy in India's Future: Insights. Gouvernance Europeenne Et Goepolotique De L’Énergie Tome 7, Paris.

JAKEDA, 2009. Solar Power Policy for J\&K '2010'. Srinagar, India.

Jammu and Kashmir State Electricity Regulatory Commission, 2010. For determination of Generic Tariff for procurement of power from wind energy generators in the State of Jammu and Kashmir. Srinagar, India.

MNRE (2011), Renewable energy in India: vision, progress and strategy. Ministry of new and renewable energy, Govt. of India, New Delhi.

Neudoerfer, R.C., Malhotra, P., Venkata Ramana, P., 2000. Participatory rural energy planning in India: a policy context. Journal of Energy Policy 29, 371-381.

Newbery,D.M., 2006. Power sector reform, Private Investment and Regional Cooperation, SAARC Business Leaders Conclave, South Asia Regional Integration and Growth.

NTPC, 2010. (Online) Available at 〈https://www.ntpc.co.in/index.php?option=com content\&view=article\&id=28\&Itemid=41\&lang=en $\rangle$ (accessed on 17.12.2010)

Planning Commission of India, 2010. (Online) Available at $\langle$ http://planningcom mission.gov.in $/\rangle$ (accessed on 03.12.2010)

Powergrid, 2010. (Online) Available at $\langle$ https://www.powergridindia.com/PGCIL NEW/contentpage.aspx? pageid=P:102 $\rangle$ (accessed on 17.12.2010)

Rodríguez Monroy, C., San Segundo Hernández, A., 2008. Strengthening financial innovation in energy supply projects for rural exploitations in developing countries. Journal of Renewable and Sustainable Energy Reviews 12, 1928-1943.

TERI, 1999. TEDDY TERI Energy Data Directory and Yearbook (1998/99). Tata Energy Research Institute, New Delhi.

TERI, 2006. National Energy Map for India: Technology Vision 2030. Tata Energy Research Institute, New Delhi.

United Nations Framework Convention on Climate Change (UNFCC), 2010a. (Online) Available at: 〈http://unfccc.int/kyoto_protocol/items/2830.php 〉 (accessed 15.12.2010).

United Nations Framework Convention on Climate Change (UNFCC), 2010b. (Online) Available at: $\langle$ http://unfccc.int/kyoto_protocol/mechanisms/clean development_mechanism/items/2718.php $\rangle$ (accessed on 15.12.2010).

World Bank, 2010. India's Power Sector. (Online) Available at: 〈http://www.world bank.org.in/WBSITE/EXTERNAL/COUNTRIES/SOUTHASIAEXT/INDIAEXTN/0, con tentMDK:22545935 pagePK: $141137 \sim$ piPK: $141127 \sim$ theSitePK:295584,00. $\mathrm{html}>$ (accessed 18.04.2010) 